\title{
Pengaruh Matos terhadap Peningkatan CBR (California Bearing Ratio)dan Sifat Kedap Airpada Tanah Sekitar Rawa Pening
}

\author{
(Studi kasus: Tanah Urug Tanggul di Jalan Lingkar Selatan Km.03 Ambarawa) \\ Erwin Harris Saputra; Lie Sanders Deckcrealy K; \\ Djoko Suwarno dan Budi Setiyadi \\ e-mail: erwinharris95@gmail.com
}

Program Studi Teknik Sipil, Fakultas Teknik

Universitas Katolik Soegijapranata, Semarang

\begin{abstract}
Rawa Pening soil contains peat has low level of California Bearing Ratio (CBR) and high permeability so it is less suitable for embankment. Above the embankment functioned as a road body. This study adds cement and matos (normal) to increase soil bearing capacity. (50\%), 50\% G 50\% Cement (C) 8\%, TSRP 50\% + G 50\% + C 8\% + Matos (M) 2\%, 4\% and $6 \%$. CBR soaked, normal results obtained CBR $2.99 \%$ while the CBR requirement of $5.44 \%$. Addition of $C 8 \%$ adds $C B R$ value to $9,25 \%$, while addition of $M 2 \%$ increase CBR value equal to 8,9\%, M 4\% yield CBR become $16 \%$ and $M$ 6\% get CBR equal to $16 \%$. Low compaction, normal soil undergoes seepage after a day, compaction is undergone seepage after 3 days and standard compaction does not undergo seepage for 7 days. The most optimal result, with stabilization of $C 8 \%$ and $M 4 \%$. Addition of $M 2 \%$ is not effective or equal to $8 \%$ cement. The addition of $M 6 \%$ equals $M 4 \%$.
\end{abstract}

Keywords: Rawa Pening soil and peat, cement, matos, permeability and CBR.

\section{Pendahuluan}

Rawa Pening terletak di Jalan Lingkar Km.03, Kecamatan Ambarawa. Rawa Pening berfungsi sebagai penampungan air untuk mencegah terjadinya banjir. Penampungan dilakukan dengan penggalian pada waduk Rawa Pening tersebut. Hasil galian tersebut biasanya dibuang begitu saja.Alangkah baiknya, jika hasil galian tersebut dimanfaatkan untuk pembuatan tanggul.

Jenis tanah sekitar Rawa Pening tersebut merupakan gambut, sehingga kurang cocok untuk pembuatan tanggul. Gambut pada Rawa Pening memiliki tingkat CBR (California Bearing Ratio) rendah dan tingkat permeabilitas tinggi. Pembuatan tanggul sekitar Rawa Pening, perlu mendatangkan tanah dari tempat lain. Hal tersebut membuat kerusakan pada tempat lain dan mengganggu ekosistem setempat. Maka diperlukan penelitian dengan menggunakan bahan setempat dicampur dengan tanah baru kemudian ditambahkan bahan tambah. Bahan tambah tersebut ialah semen dan matos.

Semen berfungsi untuk mengeraskan dan meningkatkan daya dukung tanah, sedangkan matos berfungsi untuk meningkatkan tingkat kedap tanah terhadap air sekaligus meningkatkan daya dukung gambut.

\section{Tinjauan Pustaka}

\subsection{Tanah}

Tanah (soil) adalah kumpulan (agregat) butiran mineral alami yang bisa dipisahkan oleh suatu cara mekanik bila agregat tersebut diaduk dalam air, sedangkan batuan (rock) merupakan 
agregat mineral yang satu sama lainnya diikat oleh gaya-gaya kohesif yang permanen dan kuat (Terzaghi dan Peck, 1967).

Struktur Perkerasan jalan terdiri dari beberapa lapis perkerasan, yaitu:

- Tanah dasar (sub grade)

- Lapis pondasi bawah (subbase course)

- Lapis pondasi (base course)

- Lapis permukaan / penutup (surface course)

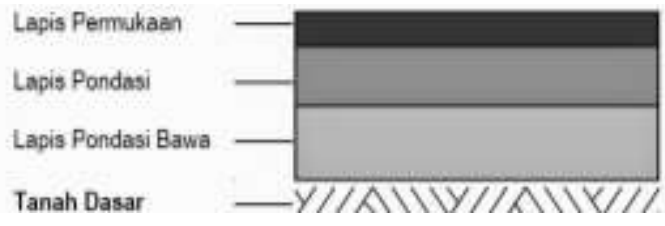

Gambar 2.1 Struktur Lapisan

Perkerasan Jalan Sumber:

(http://www.kumpulengineer.com/201 4/05/tanah-dasar-sub-gradestruktur.html)

Tanah dasar adalah lapisan tanah paling bawah yang berfungsi sebagai tempat perletakan lapis perkerasan dan mendukung konstruksi perkerasan jalan di atasnya.

\subsection{Gambut}

Gambut berasal dari serat-serat flora dan fauna yang telah mengalami pelapukan dan pembusukan. Gambut memiliki kadar air dan tingkat kompresibilitas yang tinggi serta daya dukung yang rendah (Wijaya, 2013).

Fisik gambut memiliki klasifikasi yang berbeda-beda. Klasifikasi tersebut dibedakan berdasarkan karakteristik kimia dan botani.

Menurut Mc Farlane (1959), gambut dibedakan menjadi 2 yaitu:

a. Fibrouse peat: kandungan serat $>20 \%$

b. Amorphous granular peat: kandungan serat $<20 \%$.

Umumnya gambut memiliki warna coklat hingga ke hitam-hitaman. Gambut sangat erat kaitannya dengan material alam yang memiliki kompresibilitas tinggi. Material alam tersebut terdiri dari jaringan nabati yang memiliki warna coklat tua sampai kehitaman dan berasal dari tumbuh-tumbuhan yang telah mengalami pembusukan (Untoro, 2008).

\subsection{Uji Kompaksi}

Kompaksi / pemadatan adalah proses dimana udara pada pori-pori tanah dikeluarkan dengan suatu cara mekanis (ditumbuk). Pada proses pemadatan untuk setiap daya pemadatan tertentu, kepadatan yang tercapai tergantung pada banyaknya air di dalam tanah tersebut, yaitu kadar airnya.Tujuan uji kompaksi adalah untuk mendapatkan kadar air optimum dan berat isi kering maksimum pada suatu proses pemadatan.

Percobaan di laboratorium yang umum dilakukan untuk mendapatkan berat volume kering maksimum dan kadar air optimum adalah Proctor Compaction Test. Pada uji Proctor, tanah dipadatkan dalam sebuah cetakan silinder bervolume $130 \mathrm{ft}^{3}$ $\left(=943,3 \mathrm{~cm}^{3}\right)$. Diameter cetakan tersebut adalah 4 in $(=101,6 \mathrm{~mm})$.Pemadatan tanah dilakukan dalam 3 lapisan (dengan tebal tiap lapisan 1 in) dan jumlah tumbukan adalah $25 \mathrm{x}$ setiap lapisan. Berat penumbuk adalah $5,5 \mathrm{lb}$ (massa $=2,5 \mathrm{~kg}$ ) dan tinggi jatuh sebesar 12 in $(=304,8$ $\mathrm{mm})$.

Berat isi kering maksimum ( $\square_{\mathrm{d} \text { max }}$ ) adalah berat isi terbesar yang dicapai pada pengujian kompaksi pada energi tertentu. Kadar air optimum adalah nilai kadar air di mana pada energi kompaksi tertentu dicapai maksimum.

Berat isi kering ( $\square$ d) dapat dihitung dari rumus:

$$
\gamma d=\frac{W}{V(1+w)}
$$

\section{Dimana:}

$\square \mathrm{d}=$ Berat isi kering maksimum

$\mathrm{V}=$ Volume tanah $\left(\mathrm{cm}^{3}\right)$

$\mathrm{W}=$ Berat contoh tanah (gr)

$\mathrm{w}=$ Kadar air $(\%)$ 
Untuk menggambarkan Zero Air Voids Curve dihitung dengan memakai rumus:

$$
\gamma_{z A V}=\frac{G s \times \gamma_{w}}{1+(w \times G s / S r)}
$$

Dimana:

Gs $=$ Berat jenis tanah

$\square \mathrm{w}=$ Berat volume air $\left(\right.$ ton $\left./ \mathrm{m}^{3}\right)$

$\mathrm{w}=$ Kadar air $(\%)$

$\mathrm{Sr}=$ Derajat Kejenuhan

\subsection{Uji CBR (California Bearing Ratio)}

CBR berguna untuk mengetahui kekuatan tanah dasar atau bahan lain yang akan pembuatan perkerasan jalan.Nilai CBR yang diperoleh lalu dipakai untuk menentukan tebal lapisan perkerasan yang diperlukan.

Semakin tinggi nilai CBR tanah (Subgrade) maka lapisan diatasnya semakin tipis dan sebaliknya semakin kecil nilai CBR (daya dukung tanah rendah) maka lapisan diatasnya semakin tebal. Ada 2 macam pengukuran CBR yaitu:

1. Nilai CBR untuk tekanan penetrasi pada penetrasi $0,254 \mathrm{~cm}(0,1 ")$ terhadap penetrasi standart yang besarnya 70,37 $\mathrm{kg} / \mathrm{cm}^{2}$ (1000psi).

$$
\mathrm{CBR}=\frac{P 1}{70,37} \times 100 \%\left(\mathrm{P}_{1} \text { dalam } \mathrm{kg} / \mathrm{cm}^{2}\right)
$$

2. Nilai CBR untuk tekanan penetrasi pada penetrasi $0,508 \mathrm{~cm}(0,2$ ") terhadap penetrasi standart yang besarnya 105,56 $\mathrm{kg} / \mathrm{cm}^{2}$ (1500psi)

$$
\mathrm{CBR}=\frac{P 2}{105,56} \times 100 \%\left(\mathrm{P}_{2} \text { dalam } \mathrm{kg} / \mathrm{cm}^{2}\right)
$$

\subsection{Uji Permeabilitas}

Permeabilitas adalah kemampuan tanah untuk meloloskan/melewatkan air.Permeabilitas tanah juga merupakan suatu kesatuan yang meliputi infiltrasi tanah dan bermanfaat sebagai permudahan dalam pengolahan tanah.Tanah dengan permeabilitas tinggi dapat menaikkan laju infiltrasi sehingga menurunkan laju air larian(Rohmat, 2009).

Dalam menghitung pemindahan air melalui tanah pada kondisi jenuh dikenal hukum Darcy yang biasa digunakan dalam menghitung permeabilitas. Hukum Darcy merupakan satu ukuran pengaliran air pada tanah jenuh dan dirumuskan sebagai berikut:

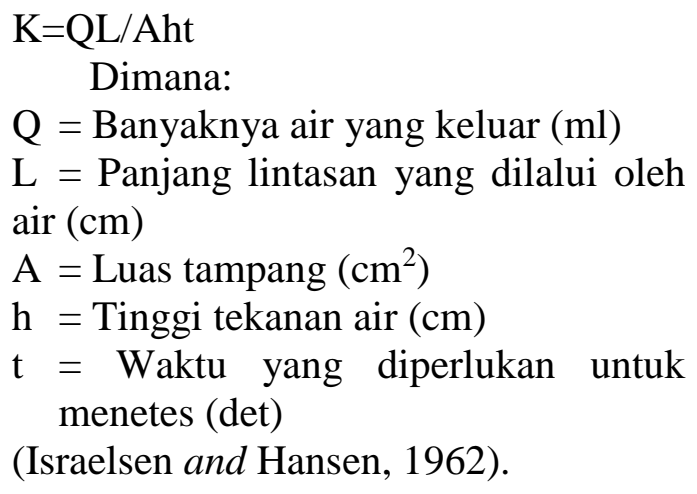

\subsection{Stabilisasi Tanah}

Stabilisasi tanah merupakan usaha untuk memperbaiki atau meningkatkan daya dukung tanah asli, dengan cara menambahkan atau mencampurkan tanah dengan suatu bahan tambah.

\subsubsection{Stabilisasi Portland Cement dan Matos}

\subsubsection{Portland Cement}

Menurut Hardiyatmo (2010), Semen Portland merupakan media perekat bila bereaksi dengan air. Media perekat ini kemudian memadat dan membentuk massa keras. Pada proses hidrasi tersebut, hasil hidrasi akan mengendap di bagian luar sedang di bagian dalam akan terhidrasi secara bertahap sehingga volumenya mengecil.

\subsubsection{Matos}

Matos merupakan ser:blol halus yang terdiri dari komposisi mineral aditif anorganik yang secara fisik dan kimia memiliki fungsi untuk memperkuat dan menstabilkan tanah. 


\section{Metode Penelitian}

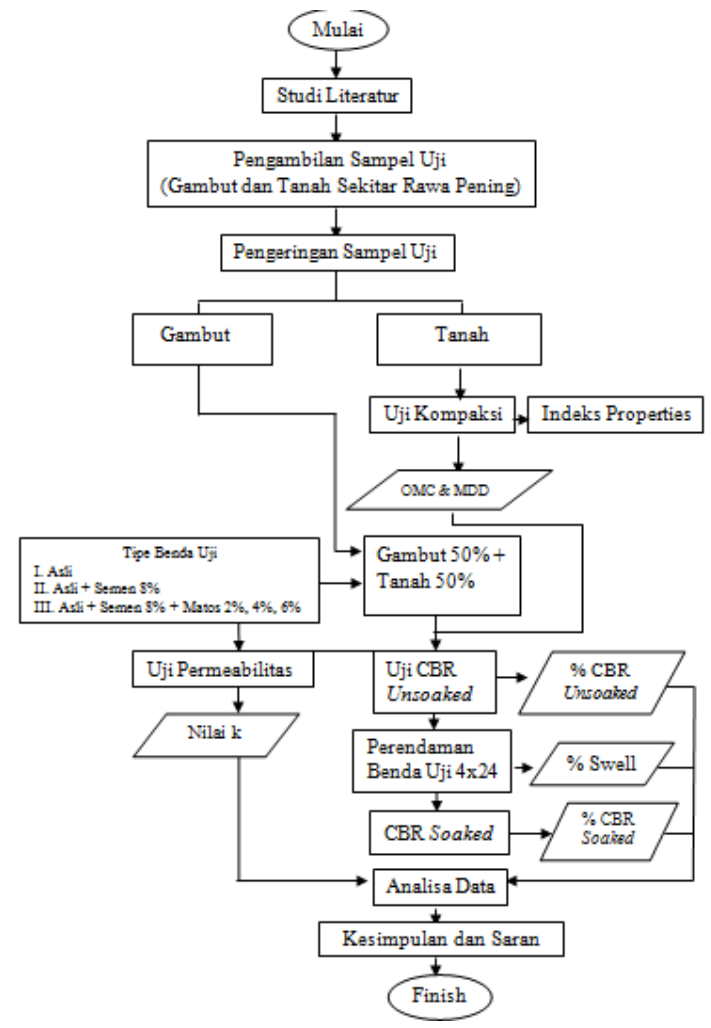

Gambar 3.1. Bagan Alir Penelitian

Terdpat 5 macam tipe benda uji, yaitu:

1. Tanah Sekitar Rawa Pening 50\% + Gambut 50\%,

2. Tanah sekitar Rawa Pening 50\% + Gambut 50\% + Semen 8\%,

3. Tanah sekitar Rawa Pening 50\% + Gambut $50 \%$ + Semen $8 \%$ + Matos $2 \%$,

4. Tanah sekitar Rawa Pening 50\% + Gambut $50 \%$ + Semen $8 \%$ + Matos $4 \%$,

5. Tanah sekitar Rawa Pening 50\% + Gambut 50\% + Semen 8\% + Matos $6 \%$.

Awal percobaan dengan melakukan uji kompaksi, dengan komposisi tanah sekitar Rawa Pening 50\% + Gambut $50 \%$ untuk mendapatkan w optimum. Setelah itu, dilakukan uji CBR dengan komposisi benda uji no.1 - no.5 sehingga dapat diketahui seberapa besar pengaruh stabilisasi semen dan matos terhadap peningkatan nilai CBR tanah sekitar Rawa Pening. Setelah uji CBR, lalu dilakukan uji permeabilitas dengan komposisi serupa untuk mengetahui tingkat kedap tanah terhadap air.

\section{Hasil dan Pembahasan 4.1. Uji Kompaksi}

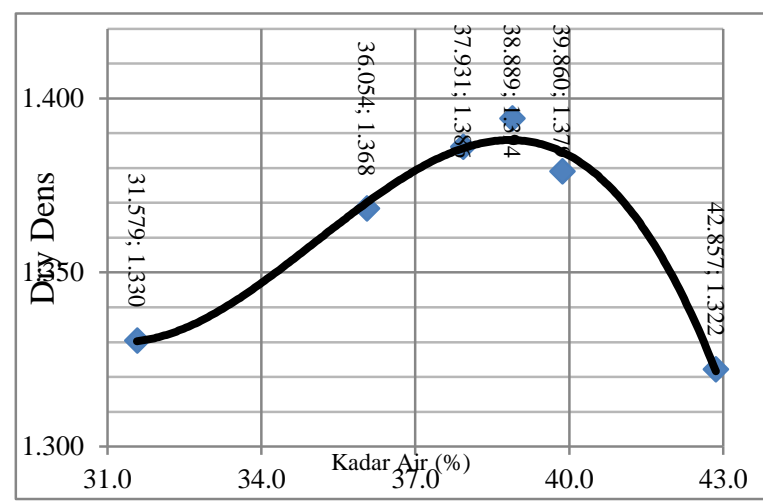

Gambar 4.1 Grafik hubungan antara kadar air dengan $\square$ dry

(Sumber: Pengolahan Hasil Penelitian, 2017)

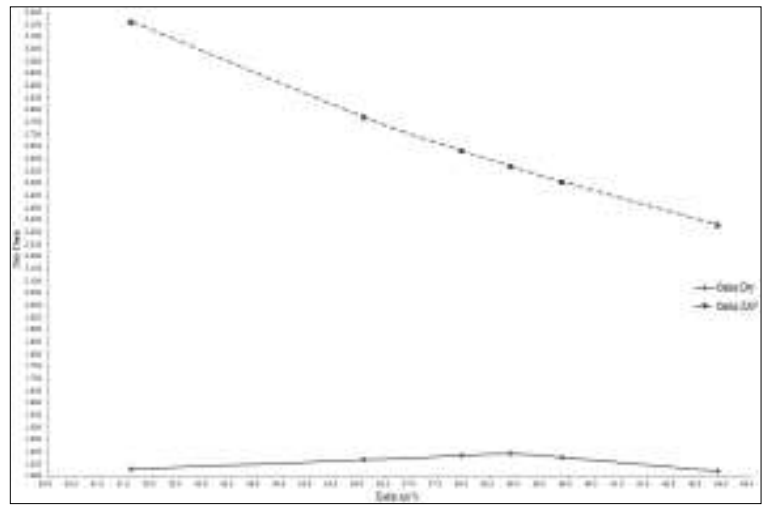

Gambar 4.2 Grafik Hubungan antara $\square$ dry dengan $\square$ ZAV

(Sumber: Pengolahan Hasil Penelitian, 2017)

Grafik pada Gambar 4.1 bertujuan untuk menemukan nilai OMC (Optimum Moisture Content) atau kadar air optimum yang diperlukan. Dari nilai OMC tersebut dihasilkan nilai MDD (Maximum Dry Density). Hasil nilai OMC pada penelitian ini adalah sebesar 39\% dengan nilai MDD sebesar 1,388 . 
Berdasarkan grafik pada Gambar 4.2 di atas, dapat disimpulkan bahwa nilai dari $\square$ dry lebih kecil daripada nilai $\square$ zAv. Hal ini berarti sesuai dengan ketentuan yang menggambarkan grafik compaction $\square$ dry tersebut akan selalu berada di bawah $\square$ zAV biasanya tidak lurus tetapi agak cekung ke atas.

\subsection{Uji CBR (California Bearing Ratio)}

Dibawah ini, akan dibahas Gambar 4.3 grafik hubungan CBR sebelum rendam (Unsoaked) dan Gambar 4.4 grafik hubungan CBR rendam (Soaked).

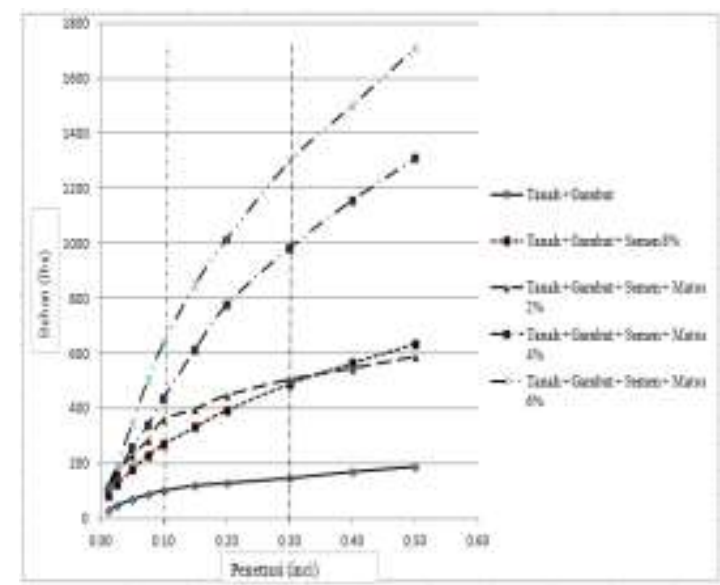

Gambar 4.3 Grafik gabungan CBR Sebelum Rendam (Unsoaked)

(Sumber: Pengolahan Hasil Penelitian, 2017)

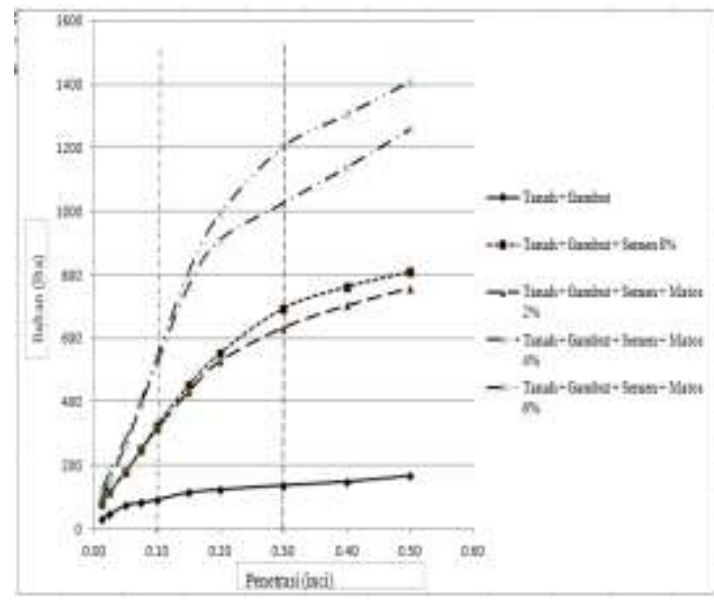

Gambar 4.4 Grafik gabungan CBR Sebelum Rendam (Soaked)

(Sumber: Pengolahan Hasil Penelitian, 2017)
Berdasarkan Gambar 4.3 dan Gambar 4.4 di atas dapat diketahui bahwa terjadi peningkatan nilai CBR yang signifikan setelah distabilisasi dengan bahan tambah yaitu semen dan matos. Dari kedua gambar pada grafik tersebut dapat dilihat bahwa penambahan matos $2 \%$ tidak efektif karena memiliki nilai CBR yang relatif sama dengan benda uji yang tidak ditambah dengan matos.

Pada Gambar 4.3 CBR sebelum rendam (Unsoaked) penambahan matos $4 \%$ pada penetrasi 0,3 inci mengalami peningkatan sebesar $\pm 50,23 \%$ dari stabilisasi menggunakan semen. Sedangkan penambahan matos $6 \%$ mengalami peningkatan sebesar $\pm 62,35 \%$ dari stabilisasi menggunakan semen. Pada Gambar 4.27 CBR rendam (Soaked) juga mengalami peningkatan, pada penambahan matos $4 \%$ dengan penetrasi 0,3 inci mengalami peningkatan sebesar $\pm 32,31 \%$ dari stabilisasi menggunakan semen. Sedangkan penambahan matos $6 \%$ mengalami peningkatan sebesar $\pm 42,38 \%$ dari stabilisasi menggunakan semen. Dengan adanya penambahan kadar matos secara umum dapat meningkatkan nilai CBR, namun pada gambar grafik di atas belum dapat menunjukkan besarnya nilai CBR yang sesungguhnya. Sesuai dengan aturan koreksi nilai CBR didasarkan pada nilai CBR pada penetrasi 0,1 inci. Untuk itu, pada di bawah ini akan ditampilkan Gambar 4.5 mengenai grafik hubungan CBR pada nilai penetrasi 0,1 inci.

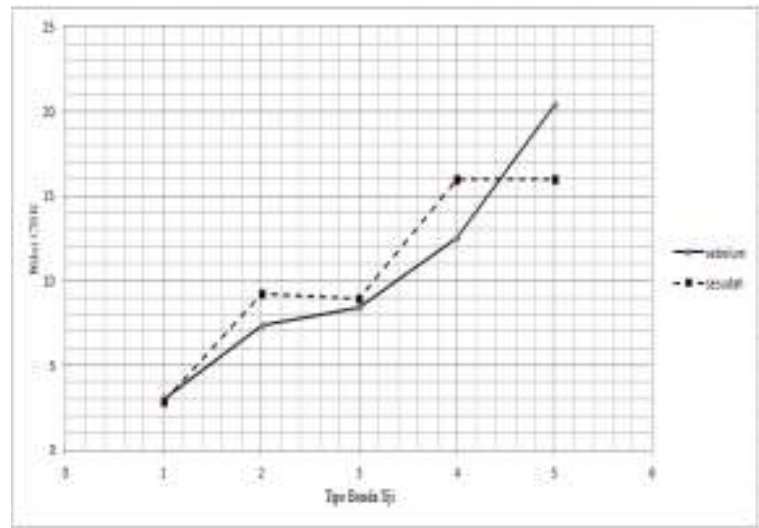


Gambar 4.5 Grafik gabungan CBR sebelum rendam (Unsoaked) dan CBR rendam (Soaked) nilai CBR pada Penetrasi 0,1 inci

(Sumber: Pengolahan Hasil Penelitian, 2017)

Berdasarkan Gambar 4.5 diatas, dapat diketahui bahwa pada nilai CBR sebelum rendam (Unsoaked) untuk penetrasi 0,1 inci setelah material ditambah dengan bahan tambah berupa semen dan matos mengalami peningkatan terus-menerus. Namun, setelah dilakukan penelitian pada CBR rendam (Soaked) untuk penetrasi 0,1 inci pada benda uji tipe 4, dapat diketahui adanya kenaikan nilai CBR dibandingkan dengan yang sebelum di rendam. Kenaikan nilai tersebut merupakan kenaikan nilai yang paling besar akibat penambahan matos $4 \%$. Sedangkan pada penambahan matos $6 \%$ justru sesudah perendaman (Soaked) menunjukkan nilai CBR yang lebih rendah dari sebelum perendaman (Unsoaked).

\subsection{Uji Permeabilitas}

Tabel 4.1 Hasil Pengamatan Permeabilitas dengan Tingkat Kepadatan Standar

\begin{tabular}{|c|r|}
\hline $\mathbf{Q}$ & \multicolumn{1}{|c|}{$\mathbf{t}$} \\
\hline $\begin{array}{c}\text { tetes I } \\
\text { (cc) }\end{array}$ & \multicolumn{1}{c|}{ detik } \\
\hline 0 & 0 \\
\hline 0 & 3600 \\
\hline 0 & 7200 \\
\hline 0 & 108000 \\
\hline 0 & 172800 \\
\hline 0 & 259200 \\
\hline 0 & 345600 \\
\hline 0 & 432000 \\
\hline 0 & 518400 \\
\hline 0 & 604800 \\
\hline
\end{tabular}

Berdasarkan tabel diatas nilai $\mathrm{k}$ tanah yang diuji adalah sebesar $=0,00 \mathrm{~cm} /$ detik .
Selain itu juga dilakuan dengan variasi tingkat kepadatan dengan hasil sebagai berikut:

Tabel 4.2 Perbandingan antar Tingkat Kepadatan untuk Uji Rembesan

\begin{tabular}{|c|c|c|c|}
\hline $\begin{array}{c}\text { Tingkat } \\
\text { Kepadata } \\
\text { n }\end{array}$ & $\begin{array}{c}\text { Renda } \\
\text { h ( 1 } \\
\text { lapis } \\
\text { @ 25x) }\end{array}$ & $\begin{array}{c}\text { Sedang } \\
\text { ( 3 lapis } \\
\text { @ 25x) }\end{array}$ & $\begin{array}{c}\text { Standa } \\
\mathbf{r} \text { (5 } \\
\text { lapis } \\
\text { @ 25x) }\end{array}$ \\
\hline Menetes & $\begin{array}{c}\text { YA } \\
\text { (setela } \\
\text { h 1 } \\
\text { hari) }\end{array}$ & $\begin{array}{c}\text { YA } \\
\text { (setelah } \\
\text { 3 hari } \\
\text { sebanya } \\
\text { k 7cc) }\end{array}$ & TIDAK \\
& & \\
\hline
\end{tabular}

Berdasarkan Tabel 4.3 pada tingkat kepadatan rendah tanah sekitar Rawa Pening 50\% + Gambut 50\% masih mengalami rembesan. Namun mulai tingkat kepadatan sedang mengalami rembesan setalah $3 \times 24$ jam. Hal ini berarti jika pelaksanaan pemadatan pada pekerjaan pembangunan tanggul Rawa Pening kurang memenuhi syarat maka material yang diuji kurang dapat diandalkan sebagai material tanggul, karena mengalami rembesan.

\section{Kesimpulan dan Saran}

\subsection{Kesimpulan}

Hasil pengamatan selama penelitian yang telah dilakukan di laboratorium terhadap tanah sekitar Rawa Pening yang distabilisasi dengan semen dan matos dapat disimpulkan bahwa:

1. Pada percobaan CBR (California Bearing Ratio), sampel tanah sekitar Rawa Pening 50\% + gambut 50\% didapatkan nilai CBR tidak rendam (unsoaked) sebesar 3,0335\%; nilai CBR rendam (soaked)sebesar 2,9915\% dengan pengembangan (swell) sebesar $8,985 \%$.

2. Pada percobaan $\mathrm{CBR}$, sampel tanah sekitar Rawa Pening 50\% + gambut $50 \%+$ semen $8 \%$ didapatkan nilai CBR unsoaked sebesar 7,367\%; nilai CBR soaked sebesar 9,25\% dengan swell sebesar $1,759 \%$. 
3. Pada percobaan CBR, sampel tanah sekitar Rawa Pening 50\% + gambut $50 \%+$ semen $8 \%+$ matos $2 \%$ didapatkan nilai CBR unsoaked sebesar 8,3835\%; nilai CBR soaked sebesar 8,9335\% dengan swell sebesar $0,605 \%$.

4. Pada percobaan CBR, sampel tanah sekitar Rawa Pening 50\% + gambut $50 \%+$ semen $8 \%+$ matos $4 \%$ didapatkan nilai CBR unsoaked sebesar 12,5335\%;nilai CBR soaked sebesar $16 \%$ dengan swell sebesar $0,193 \%$.

5. Pada percobaan CBR, sampel tanah sekitar Rawa Pening 50\% +gambut $50 \%+$ semen $8 \%+$ matos $6 \%$ didapatkan nilai CBR unsoaked sebesar 20,417\%; nilai CBR soaked sebesar $16 \%$ dengan swell sebesar $0,418 \%$.

6. Pada percobaan CBR, dengan penambahan matos $2 \%$ hasilnya tidak efektif karena memiliki nilai CBR yang relatif sama dengan benda uji yang tidak ditambah matos.

7. Pada percobaan CBR, tanpa adanya penambahan bahan tambah berupa matos pun, ternyata tanah sekitar Rawa Pening sudah memenuhi syarat nilai CBR untuk jalan.

8. Pada percobaan CBR, didapatkan hasil paling optimal adalah dengan menggunakan stabilisasi semen $8 \%$ dan matos $4 \%$ dengan nilai CBR unsoaked sebesar 12,5335\%; CBR soaked sebesar $16 \%$ dan swell sebesar $0,193 \%$. Meskipun pada stabilisasi dengan menggunakan semen $8 \%$ dan matos 6\% memiliki nilai CBR unsoaked lebih besar, namun setelah dilakukan perendaman mengalami penurunan nilai CBR sebesar 21,634\%. Sedangkan sampel tanah yang distabilisasi dengan semen $8 \%$ dan matos $4 \%$ justru mengalami peningkatan nilai CBR sebesar $27,66 \%$.
9. Pemadatan harus dilakukan sesuai dengan desain tingkat pemadatan (CBR 16\%), agar tidak terjadi rembesan pada material pembuatan tanggul. Hal tersebut sesuai dengan hasil pembahasan pada Tabel 4.2. Jika pelaksanaan pemadatan pada pekerjaan pembangunan tanggul Rawa Pening kurang memenuhi syarat, maka material yang diuji kurang dapat diandalkan sebagai material tanggul, karena mengalami rembesan.

10. Hasil pengujian permeabilitas mengidentifikasikan sebagai material lanau $(0.001>\mathbf{0 . 0 0 0 0 2 7}>0.00001)$, hal ini sesuai juga dengan klasifiasi USCS.

\subsection{Saran}

Berdasarkan hasil pengamatan selama penelitian dapat disampaikan saran sebagai berikut:

1. Dapat dilakukan penelitian lanjutan dengan persentase tanah dan gambut yang berbeda.

2. Dapat dilakukan penelitian lanjutan dengan bahan tambah matos, namun terdapat variasi pada kadar semen.

3. Batas waktu pencampuran semen yaitu 30 - 45 menit.

4. Diperlukan penelitian CBR dengan masa perawatan yang lebih bervariatif.

5. Diperlukan jangka waktu lebih dari 7 hari untuk penelitian tingkat kedap air, agar didapatkan hasil yang lebih maksimal.

\section{Daftar Pustaka}

Hardiyatmo, H.C., (2010), "Stabilisasi Tanah untuk Perkerasan Jalan", Gajah Mada University Press, Edisi pertama, Yogyakarta.

Israelsen, and Hansen, (1962), Irrigation Principles and Practices, Willey, New York. 
Mc Farlane, I.C., (1959), “A Review Of The Engineering Characteristics of Peat", Journal of Soil Mechanics and Foundation Devision, SM-1, pp, 2135 .

Rohmat, (2009), Dasar-Dasar Ilmu Tanah, Erlangga, Jakarta.

Terzaghi, K dan Peck, R.B, (1967), Mekanika Tanah Dalam Praktek Rekayasa, Erlangga, Jakarta.

Untoro, (2008), "Stabilisasi Tanah Gambut Rawa Pening dengan Menggunakan Campuran Portland Cement dan Gypsum Sintetis", Fakultas Teknik Universitas Negeri Semarang, Semarang, Skripsi.

Wijaya, Rudi, (2013), “Analisa Sistem Konstruksi di Atas Tanah Gambut dengan Menggunakan Program Sigma/W', Universitas Indonesia, Jakarta, Skripsi. 